\title{
ジフェニルカルバゾン法による微量塩化物イオン 定貫法の改良
}

\author{
吉永鐵大郎®，井浦登志実，河野賢太郎*
}

(1987 年 9 月 9 日受理)

\begin{abstract}
微量（1 ppm 以下）の塩化物イオンの間接吸光光度定量法であるジフェニルカルパゾン法は優れた方 法ではあるが, 再現性に問題があるため, それについて基礎的研究を行った。その結果, 液温を一定に 保ち，十分な遮光下で，水銀混合陚薬として硝酸水銀 (II) $\left(1.0 \times 10^{-4} \mathrm{M}\right)+$ 臭化水銀 $(\mathrm{II})\left(0.5 \times 10^{-4}\right.$ M) の $1 \times 10^{-2} \mathrm{M}$ 硝酸溶液を $2 \mathrm{ml}$ 用い (試料溶液 $10 \mathrm{ml}$ ), ベンゼン $10 \mathrm{ml}$ を抽出試薬として加兄, 次いでジフェニルカルバゾン試薬 $(\mathrm{DG}$ 試薬，ジフェニルカルバン゙ンとジフェニルカルバジドの等モル 混合物) $0.05 \mathrm{~g}$ を $100 \mathrm{ml}$ エタノールに溶解したもの $2 \mathrm{ml}$ を加え，振り混せ速度と時間を一定とし， 振り混ぜ前後の放置時間にも注意して溶媒抽出を行えば，再現性と直線性の良好な検量線が得られるこ とが分かった。特に DG 試楽についてはジフェニルカルバゾンとジフェニルカルバジドの含有率が各 各 50〜70\% 及び 50〜30\% の範囲に西るものが望ましい．
\end{abstract}

\section{1 緒言}

天然水, 飲料水, 工業用水, 八イテク産業に拈ける洗 浄水，あるいは種々の下・排水中に批ける塩化物イオン の定量は水質検査に㨃ける基本的な項目の一つになって いる．実際，塩化物イオンに関しては多くの定量法が提 出されているが微量の測定が可能なものは少ない，吸光 光度法ではチオシアン酸水銀(II) 法 ${ }^{12)}$ ，溶媒抽出を利 用するジフェニルカルバゾン法3)4), 水銀クロラニル酸塩 法5)などがあり，これに関連して比濁法6) も挙げることが できよう。特に $1 \mathrm{ppm}$ 以下の 微量塩化物イオンの測定 法としてジフェニルカルバゾン法が推奖されている7).

著者らはイオンクロマトグラフィーなどの特別の機器を 必要とする方法はさて扣き，比較的簡便に測定できる方 法として友成 ${ }^{3)}$, 内海ら ${ }^{4)}$ の提出したジフェニルカルバジ ン (DG) 法を用いて; 試料中の微量塩化物イオンの定 量を試みたが，予期に反して再現性が良好ではなかっ た．そこで，著者らはこの $\mathrm{DC}$ 法が高感度であるとい ら利点を生かすため，再現性に影響を及ぼすと思われる 諸因子を検討することにした.

\section{2 実験}

\section{1 試 薬}

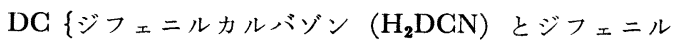

* 九州工業大学工学部 : 804 福岡県北九州市戸畑区 仙水町 1-1
カルバジト $\left(\mathrm{H}_{4} \mathrm{DCN}\right)$ の等モル混合物\} は和光純薬工 業製の試薬特級を用いた。 その他の試薬も（特級品のな いものを除き）すべて和光純薬工業の試薬特級を用い た.

$10^{-2} \mathrm{M}$ 硝酸水銀 (II) 標準溶液：硝酸水銀 (II) を計 算量量りとり濃硝酸 $8 \mathrm{ml}$ を加兄溶解し, 超純水で希釈 し, 全量 11 とした (このとき硝酸浱度約 $0.1 \mathrm{M}$ )。こ れを水銀滴定法及び AAS で濃度決定し, 保存原液とし た。必要に応じて適宜希釈した。

塩化物イオン標準溶液 $(1000 \mathrm{mg} \mathrm{Cl}-/ \mathrm{l}), 10^{-2} \mathrm{M}$ 臭 化カリウム標準溶液及び $10^{-2} \mathrm{M}$ 臭化水銀 (II) 標準溶 液: それぞれ, 計算量ずつ量りとり, 超純水で溶解し, 全量を 11 とした。これらを適宜希釈して使用した。

$\mathrm{DC}$ 試薬溶液 : DC $0.05 \mathrm{~g}$ を量りとりェタノールに溶 解し全量を $100 \mathrm{ml}$ とした。沪紙（No. 1) で沪過した 後褐色瓶に保存した，水銀を含む試薬類は褐色瓶に保存 した。

$\mathrm{pH}$ 緩重溶液 $(\mathrm{pH} \cong 2.8): p$-トルエンスルホン酸 $(p$ TSA)-p-トルエンスルホン酸ナトリウム $(p$-STSA), ク エン酸ー水酸化ナトリウムの調製は, 常法8) に従った.

\section{$2 \cdot 2$ 装置及び器具}

装置及び器具は次のものを使用した。AAS 装置：日 本ジャーレル・アッシュ製 $\mathrm{AA}-8200$ 型, 分光光度計： 囟津製作所製 UV-200 型, 超純水製造装置：日本ミリ ポフ製 Milli-QII 型, 振り混ぜ機：ヤマト科学製 SA31 型, 照度計 : 東京光電製 ANA-999 型, $\mathrm{pH} / \mathrm{mV}$ × 一ター: Bionics Instrument 製 DP-1400 型, 水銀イオ 乙電極：東興科学製，参照電極：東興科学 MR501-DS 型, 分液漏斗(白色及び褐色) : スキューブ型 $(100 \mathrm{ml})$. 


\section{3 実験操作}

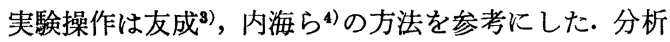
の基本原理は一定 (過剰) 量の水銀イオンが試料中の塩 化物イオンと反応し， 難解離性の 塩化水銀(II) を生成 $し\left(\mathrm{Hg}^{2+}+2 \mathrm{Cl}-\rightleftarrows \mathrm{HgCl}_{2}\right)$, 残存水銀イオンが $\mathrm{H}_{2} \mathrm{DCN}$ と有色の錯体を形成することを利用するものである．本 研究では因子を一つずつ検討するため，Fig. 1 のよう な仮標準条件を設定した、フローチャート横の数字は実 験の各ステップを示したもので, (5は試薬添加後, 振り 混ぜ開始までの放置時間を考慮したものである. 水分は 沪紙切片と無水硫酸ナトリウムで除去した.

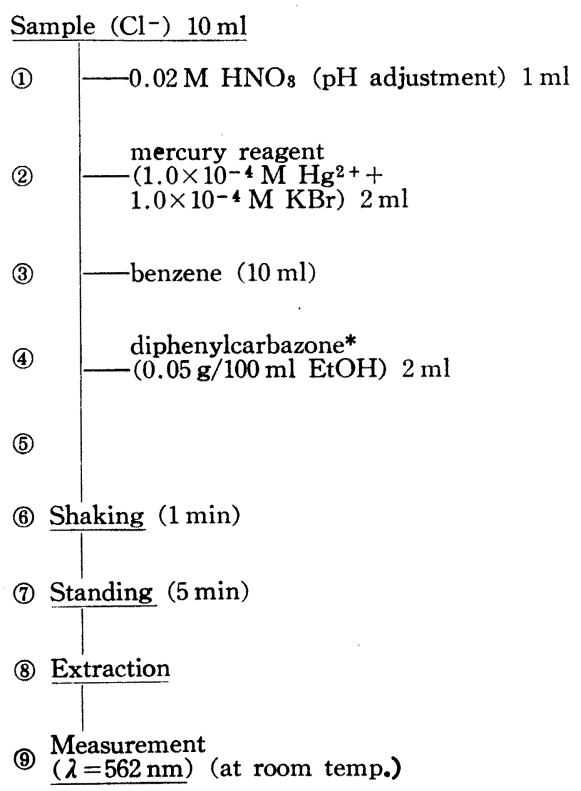

Fig. 1 Experimental procedure for the $\mathrm{Cl}^{-}$determination by the diphenylcarbazone method (Tentative standard procedure)

The number in a circle indicates respective step in the procedure that might influence the reproducibility of the analytical results. * Equimolar-mixture of diphenylcarbazone and diphenylcarbazide

\section{3 結果及び考察}

\section{1 水銀試菜の影響}

友成 ${ }^{33}$ は DC 法が微量塩化物イオンの定量に適してい ることを示したが検量線は湾曲し, 直線性がなかった. そこで内海ら4) はこの方法を検討し，主として水銀試薬 に改良を加え，硝酸水銀(II) 溶液に 等モル濃度の臭化 カリウムを混合したものを用いると検量線の直線性が良
好になることを示した．著者らはまず，この臭化カリウ 么涯加がどのような効果を及济すかを考光，塩化物イオ ンと同様に, $\mathrm{Hg}^{2+}+2 \mathrm{Br}^{-} \rightleftarrows \mathrm{HgBr}_{2}$ の反応で臭化水銀 (II) が生じ，この臭化水銀(II) が塩化水銀(II) と何ら かの相互作用を行い塩化水銀(II) の解離を抑制するも のと推測した. このことを確かめるため Fig. 2 に示す ように塩化水銀 (II), 臭化水銀 (II) 及びそれらの混合物 の各溶液を調製し，水銀イオン電極を用いて解離度 $\alpha$ を 求めた。ただし，臭化水銀 (II) の解離は約 $10^{-6.7} \mathrm{M}$ 以 上の濃度では無視できるので混合物溶液の水銀濃度とし ては塩化水銀(II) の濃度のみを考慮した. Fig. 2 は明 らかに著者らの予測を裏付けるものである.すなわち, 混合物溶液の解離度は塩化水銀 (II) 単独溶液の解離度よ りかなり抑制されたものとなっている．次に水銀試薬と 乙て硝酸水銀 $(\mathrm{II})+$ 臭化水銀 $(\mathrm{II})$ 溶液を用いて塩化物 オンの検量線を作成したところ, 予想より直線性のよい ものが得られたので，更に臭化水銀 $(\mathrm{II})$ 濃度を変えて 実験を行った. 結果を Fig. 3 に示すが臭化カリウムと 同濃度（臭素に関して）の臭化水銀(II) を用いたときが 最も直線性が良好であった，次に水銀試薬間の比較を行 った．結果を Fig. 4(a) に示すが 3 者中では臭化水銀 (II) 添加のものが最も直線性が高い，臭化カリウム添 加のものがあまり良くないのは内海らの条件と異なるた めであろう．臭化カリウム添加水銀試薬を用いた場合に 吸光度が最も高いのは, 3.9 でも述べるが, $\mathrm{Hg}^{2+}+\mathrm{Br}^{-}$ $\rightleftarrows \mathrm{HgBr}^{+} \rightleftarrows 1 / 2 \mathrm{HgBr}_{2}+1 / 2 \mathrm{Hg}^{2+}$ の反応で生じた $\mathrm{HgBr}^{+}$が $\mathrm{H}_{2} \mathrm{DCN}$ と反応し新たな有色錯体を生じるた

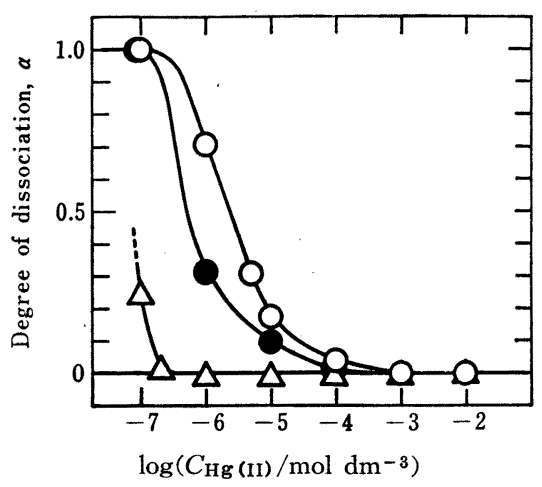

Fig. 2 Relationship between degree of dissociation and concentration of mercury chloride at room temperature $\left(\sim 15^{\circ} \mathrm{C}\right)$

$\bigcirc: \mathrm{HgCl}_{2}, \quad \triangle: \mathrm{HgBr}_{2}, \quad \bigcirc: \mathrm{HgCl}_{2}+\mathrm{HgBr}_{2}$ $(1: 1) . \mathrm{Hg}^{2+}$ concentrations were determined using $\mathrm{Hg}$-ion selective electrode. 


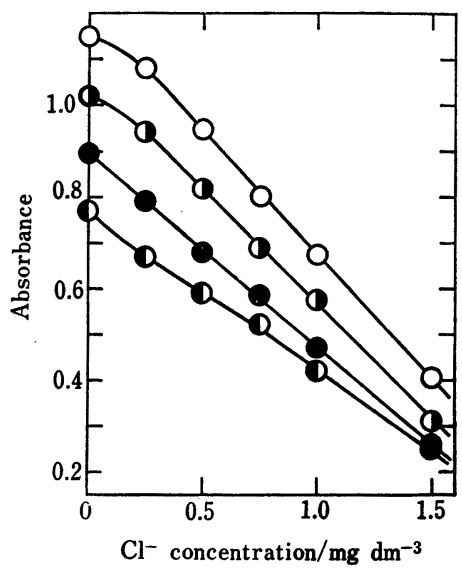

Fig. 3 Effect of addition of $\mathrm{HgBr}_{2}$ on the calibration curves for chloride ion

$\mathrm{HgBr}_{2}\left(\times 10^{4} \mathrm{~mol} \mathrm{dm}^{-3}\right): \bigcirc 1.00,(0.75$, - 0.50, 0.25. Absorbance were measured at room temperature $\left(\sim 13^{\circ} \mathrm{C}\right)$.

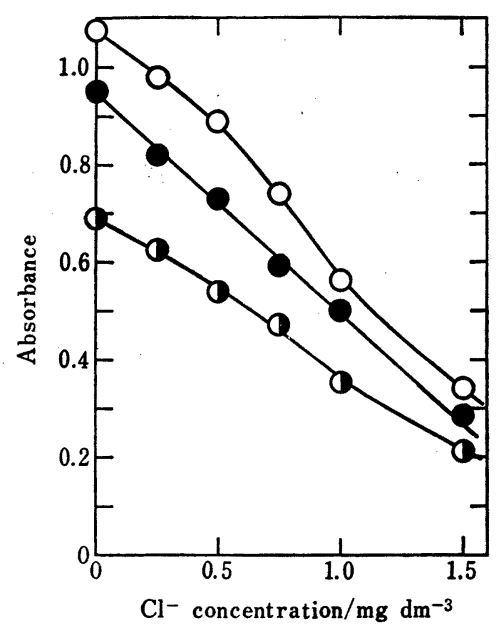

Fig. 4 (a) Effect of mercury reagents on the calibration curves for chloride ion

(1) $1.0 \times 10^{-4} \mathrm{M} \mathrm{Hg}\left(\mathrm{NO}_{3}\right)_{2}, 1.0 \times 10^{-4}$ $\mathrm{MHg}\left(\mathrm{NO}_{3}\right)_{2}+0.5 \times 10^{-4} \mathrm{M} \mathrm{HgBr}_{2}, \mathrm{O} 1.0$ $\times 10^{-4} \mathrm{M} \mathrm{Hg}\left(\mathrm{NO}_{3}\right)_{2}+1.0 \times 10^{-4} \mathrm{M} \mathrm{KBr}$

めと考えられる.しかし，単独ではほとんど解離しない 臭化水銀 $(\mathrm{II})$ が硝酸水銀 $(\mathrm{II})$ と共存すると硝酸水銀 $(\mathrm{II})$ 単独の場合より高い吸光度を示す理由が 分からないた め, 塩化水銀 (II) 又は臭化水銀 (II) 溶液を水銀試薬と して用いてみた. Fig. 4(b，c) に結果を示すが塩化水銀 (II), 臭化水銀 (II) いずれの場合も塩化物イオン濃度に よらずほぼ一定となっている，又，水銀濃度の差と吸光

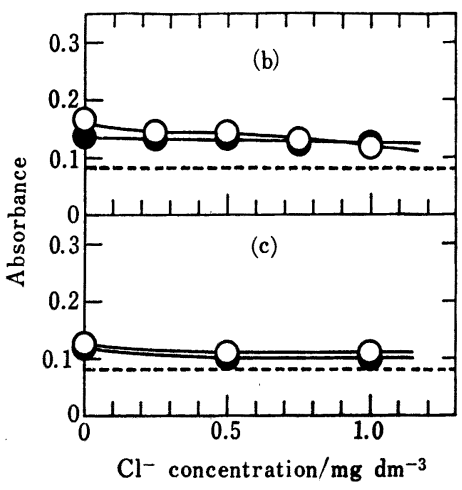

Fig. 4 (b, c) Effect of $\mathrm{HgBr}_{2}$ and $\mathrm{HgCl}_{2}$ as mercury reagents on the calibration curves for chloride ion

(b) $: \bigcirc 1.0 \times 10^{-4} \mathrm{M} \mathrm{HgCl}_{2}, \bigcirc 1.0 \times$ $10^{-4} \mathrm{M} \mathrm{HgBr}_{2}$; (c) : $\bigcirc 0.5 \times 10^{-4} \mathrm{M}$ $\mathrm{HgCl}_{2}$, $0.5 \times 10^{-4} \mathrm{M} \mathrm{HgBr}$. Dashed line indicates blank (without mercury).

度差が対応していないので水銀塩無添加で実験すると， 塩化物濃度に無関係にから試験值として約 0.08 (破線) の值が得られた.この補正を行うと塩化水銀(II) 又は臭 化水銀 $(\mathrm{II})$ に上る吸光度はほぼ水銀濃度に比例したもの となった。この值は小さいので Fig. 4(a) の差は説明 できない. 以後の実験では水銀試薬として $1.0 \times 10^{-4} \mathrm{M}$ 硝酸水銀 $(\mathrm{II})+0.5 \times 10^{-4} \mathrm{M}$ 臭化水銀 $(\mathrm{II})$ 溶液を用い, 試料 $10 \mathrm{ml}$ に対し, $2 \mathrm{ml}$ 添加することにした.

\section{2 水銀混合試薬及び DC 試薬の保存安定性}

本法は一連の実験を一定時間内に行ら場合にはばらつ きが小さいことが分かったので，日時をずらせて試薬調 製した．本水銀試薬は 4 日間安定であったが 5 日を過ぎ ると徐々に吸光度が減少した. 水銀塩の部分加水分解や 器壁への吸着がその理由と考学られるが，保存性には同 時に添加してある硝酸濃度も関係する。一方，DC 溶液 は時間経過と共に吸光度が増大し， 5 日以上経過したも のは吸光度一定となった。これは $\mathrm{DC}$ 溶液中の $\mathrm{H}_{4} \mathrm{DCN}$ が徐々に酸化され $\mathrm{H}_{\mathbf{2}} \mathrm{DCN}$ となり全体として安定なモ ル比になったためと思われる。長島ら910) は市販 DC 試 薬の多くは $\mathrm{H}_{4} \mathrm{DCN}$ と $\mathrm{H}_{2} \mathrm{DCN}$ が等モル混合物ではな 〈不安定であるが $\mathrm{H}_{2} \mathrm{DCN}$ : 50〜 70\%， $\mathrm{H}_{4} \mathrm{DCN}$ : 50〜 $30 \%$ の割合のるのは極めて安定であると報告している. このことは DC が $\mathrm{H}_{2} \mathrm{DCN}$ と $\mathrm{H}_{4} \mathrm{DCN}$ の単なる混合 物ではなくある種の分子間化合物を形成していることを 示唆している， $\mathrm{H}_{4} \mathrm{DCN}$ は単独では $\mathrm{Hg}^{2+}$ イオンとの 
錯形成能が小さい(1)ことが知られており本結果とも矛盾 しない。

\section{3 振り混ぜ条件の影響}

本法の再現性が良好でない理由の一つに振り混ぜ条件 の影響があるので検討した．振り混ぜは手によるものと 機械によるものの両方を行った．Fig. 5(a) は手による ものの結果であるが 30 秒付近で吸光度最大となってい る. 以後，手による場合は 30 秒と定めた. Fig. $5(\mathrm{~b} \sim \mathrm{d})$ に機械振り混ぜの結果を示すが，振り混ぜ条件によって 吸光度対 振り混ぜ時間のパターンが大きく異なってい る. 吸光度が最大に達する時間は振り混ぜ速度が大きい ほど短いが, 最大に達した後, 減少傾向に転じている. このことは溶媒抽出の過程で分配平衡に向からと同時に 生成錯体の分解も生じていることを示している.

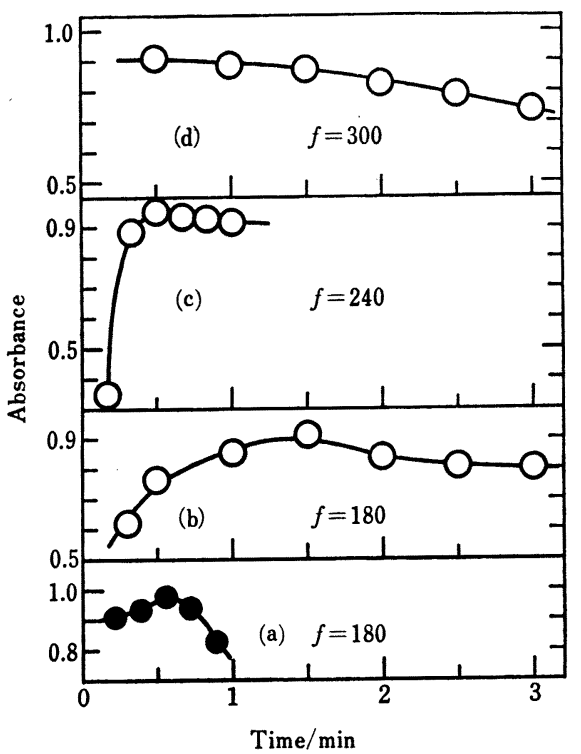

Fig. 5 Effect of shaking time and frequencies on the absorbance of $\mathrm{Hg}$-diphenylcarbazone (DC) complex

(a) : manual shaking; (b), (c) and (d) : mechanical shaking; (b) horizontal shaking; (c) and (d) vertical shaking; $f$ : shaking speed (times/min)

\section{4 放囬時間の影幚}

内海ら4は $\mathrm{Hg}-\mathrm{H}_{2} \mathrm{DCN}$ 錯体をベンゼン相に抽出後, 吸光度測定までの時間を変え, 褐色分液漏斗では 20 分 間安定, 遮光漏斗では 30 分以上安定なことを示した.

著者らは他の条件は一定とし, DG 試薬添加後, 振り 混ぜ開始までの放置時間（a），及び振り混ぜ終了直後か らベンゼン相を分離するまでの放置時間（b）の影響を 調べた。振り混ぜ前放固時間 対 吸光度の関係を Fig. 6(a) に示すが，試薬添加後約 2 分で吸光度が極小となり 以後増大を続け 10 分以後はほぼ一定となっている。こ の理由は何らかの 相反する効果が 重なったためであろ う。例えば本錯体は水相中では不安定で経時的に分解す るが，他方，水相はベンゼン相と接触しており，拡散に より錯体が移動するので一定時間後，振り混ぜを開始す ると見掛けの抽出率が上昇することが考えられる．振り 混ぜ直後からの放置時間 対 吸光度の関係を Fig. 6(b) に示すが，最初の 5 分間は安定であるが以後徐々に減少 した. 別な実験により， $\mathrm{Hg}-\mathrm{H}_{2} \mathrm{DGN}$ 錯体をべンゼン相 に移し分離後, 遮光共栓三角フラスュ中に入れ冷暗所で の経時変化を調べた．その結果，遮光してベンゼン相に 移した錯体は，分離直後のものも 2 週間後のものも吸収 スペクトルの形と強度がほとんど変わらず安定なことが 分かった.このように振り混ぜ前後の放置時間は注意を 要する。

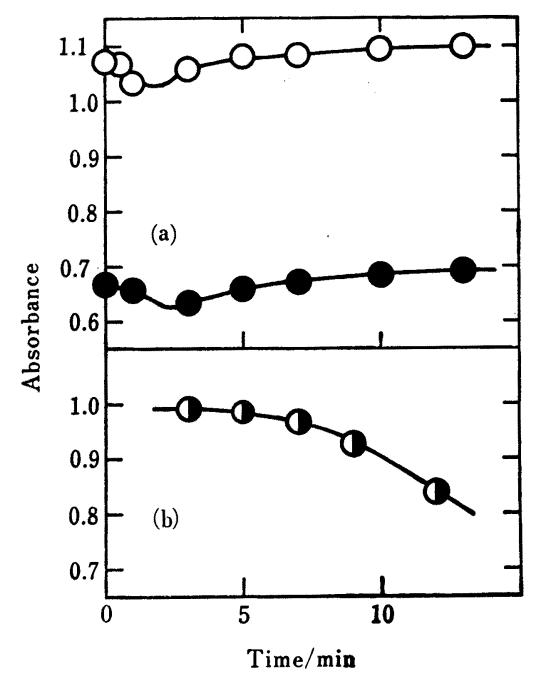

Fig. 6 Effect of standing time before (a) or after (b) shaking on the absorbance of $\mathrm{Hg}-\mathrm{DC}$ complex

In this experiment, separation funnels were manually shaken. $\bigcirc, \bigcirc:\left[\mathrm{Cl}^{-}\right]=0 ; 0$ : $\left[\mathrm{Cl}^{-}\right]=0.5 \mathrm{mg} \mathrm{dm}^{-3}$

\section{5 光の影響}

DC 法が光の影響を受けることは知られているが，定 量的検討はなされていないので照度計を用いて調べてみ 
た. $40 \sim 70 \mathrm{Lx}$ では遮光, 褐色, 白色いずれの分液漏斗 でも大差ないが, 通常の室内蛍光灯点灯下の照度に対応 する 400〜 $500 \mathrm{Lx}$ では白色分液漏斗は大きな影響（約 $30 \%$ ）を受ける。空際の照度は数千 Lx 以上に及ぶこと もあり, 変動も激しいので室内中央付近か, 照度一定の 場所を使うほうがよい. ダンボール箱 $(50 \times 45 \times 65 \mathrm{~cm}$ 程度）を用い内側を目張りし，黒色スプレー塗装してお けば蛍光灯点灯下でも $30 \mathrm{Lx}$ 以下に保つことができる (Fig. 7). $\mathrm{Hg}-\mathrm{H}_{2} \mathrm{DCN}$ 錯体が光によって退色するのは 光分解 (光化学反応) によるものであるが詳細は不明で ある・

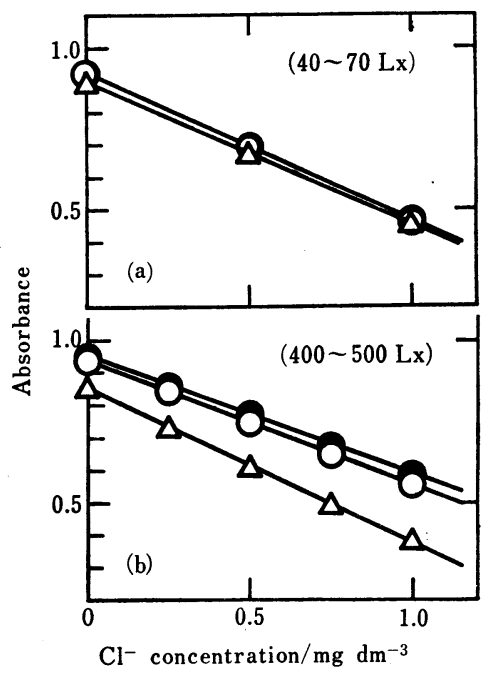

Fig. 7 Effect of light on the absorbance of the Hg-DG complex

Separation funnels : $\triangle$ clear, $\bigcirc$ brown, brown + black cloth

\section{6 pH の影響}

$\mathrm{pH}$ 調整に硝酸を用いた場合 : $\mathrm{pH}$ 值は吸光度や検量 線の形に大きな影響を及ぼす3)4). 本水銀試薬 $\left(\mathrm{HgBr}_{2}\right.$ 添加のもの）を用いた場合の $\mathrm{pH}$ の影響を調べた。 $(0.5,1.0,2.0,3.0) \times 10^{-2} \mathrm{M}$ の硝酸各 $1 \mathrm{ml}$ を添加し (水溶液の $\mathrm{pH}: 3.0,2.8,2.3,2.0$ ), それぞれの検量線 を調べたところ約 $\mathrm{pH} 2.8$ のときに直線性が最も良好で あり, $\mathrm{pH}$ が低いほど吸光度も低いといら内海らと同様 の結果が得られた Fig. 8 に吸光度の $\mathrm{pH}$ 依存性を示 す.一般に錯体の溶媒抽出を利用する分析法では関与す る配位子その他の種が $\mathrm{pH}$ の影響を受け抽出率, 反応率 などが変化するが，本法に抢ける $\mathrm{pH}$ の分析反応への寄 与は明らかではない。

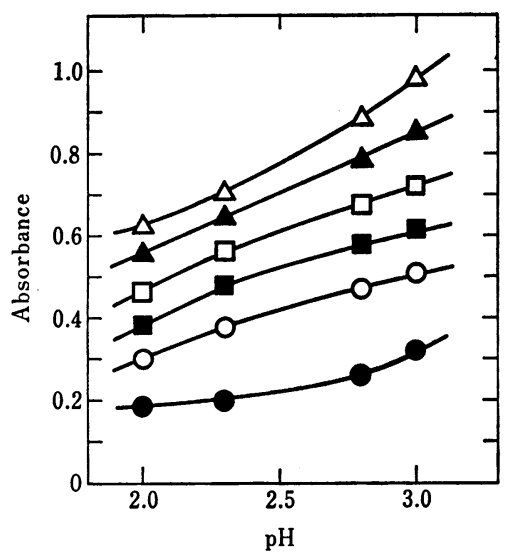

Fig. 8 Relationship between $\mathrm{pH}$ and absorbance of $\mathrm{Hg}-\mathrm{DC}$ complex

$\mathrm{pH}:$ measured at water phase (room temp. $\sim 15{ }^{\circ} \mathrm{C}$ ); Chloride concentration : $\triangle$ blank, $\triangle 0.25 \mathrm{ppm}, \square 0.50 \mathrm{ppm}, \square 0.75 \mathrm{ppm}$, $1.00 \mathrm{ppm}, 1.50 \mathrm{ppm}$

$\mathrm{pH}$ 緩衝液を用いた場合： $\mathrm{pH} 2.8$ の緩衝溶液 2 種 (a) $p$-TSA-p-STSA，（b） クェン酸-水酸化ナトリ ウム, を調製し各 $3 \mathrm{ml}$ を硝酸の代わりに添加した. (a) の場合, 硝酸添加の場合の約半分の吸光度となっ た $\left(\left[\mathrm{Cl}{ }^{-}\right]_{0}=0: \mathrm{Abs}=0.419,\left[\mathrm{Cl}^{-}\right]_{0}=1.0 \mathrm{mg} / 1: \mathrm{Abs}\right.$ =0.196). 一方, ( b ) の場合, 塩化物イオン濃度によ らずほぼ一定の吸光度 $(\mathrm{Abs}=0.247 \sim 0.230)$ となった. これは水銀イオンが緩衝溶液成分と反応し錯形成したた めであろら。

ところで，硝酸水銀原液調製時に $[\mathrm{Hg}]_{0}=1.0 \times 10^{-2}$ M として, 同時に添加する硝酸濃度を 100 倍 (1 M) としておけば, 水銀試薬は $2.0 \times 10^{-4} \mathrm{M}$ 硝酸水銀(II) 溶液と $1.0 \times 10^{-4} \mathrm{M}$ 臭化水銀 $(\mathrm{II})$ 溶液の等量混合によ り調製でき, $\mathrm{pH}$ 調整のための硝酸添加の操作は省略で きる。

\section{7 温度の影響}

本法の水銀試薬を用いて温度効果を調べた. $13^{\circ} \mathrm{G}$, $15^{\circ} \mathrm{C}, 19^{\circ} \mathrm{C}$ の 3 点について実験を行ったところ, いず れの検量線も直線性が良く, 傾きの等しいものが得られ た. 温度の高いほらが吸光度が低く, 液温が上昇すると 錯体の 分解反応が 進行しやすいものと思われる. $6^{\circ} \mathrm{C}$ 差で吸光度に 0.07〜0.08 の差が生じているので注意を 要する. 


\section{8 検量線作成条件}

以上の結果から, 遮光下, 定温, $\mathrm{pH} 2.8$ とし, 振り 混ぜなどの他条件を商切に選び $(\lambda=560 \mathrm{~nm})$ 検量線を 作成すると $\left[\mathrm{Cl}^{-}\right]_{0} \cong 1.5 \mathrm{mg} / 1$ まで直線性の良いものが 得られた。繰り返し再現性は相対標準偏差で $1.6 \%$ で あった $\left\{\left[\mathrm{Cl}^{-}\right]_{0}=1.0 \mathrm{mg} / \mathrm{l}(n=6)\right\}$. ただし $1.0 \mathrm{mg} / \mathrm{l}$ に拈ける吸光度は約 0.5 と高い值であった。

\section{9 分析反応メカニズムの検討}

DC 法による塩化物イオン定量法の基本原理は既飞述 べたが，内海らは水銀試薬として硝酸水銀(II) と等モル の臭化カリウムを添加すると検量線の直線性が良好にな ることを示した．著者らは最初 $\mathrm{Hg}^{2+}$ と $\mathrm{Br}^{-}$が反応し て $\mathrm{HgBr}_{2}$ が主に生成すると考光，水銀混合試薬に臭化 水銀(II) を添加することにした. Okutani の研究11)によ れば, $\mathrm{Hg}^{2+}+\mathrm{Br}^{-} \rightleftarrows \mathrm{HgBr}^{+}$によって生じた $\mathrm{HgBr}^{+}$ が $\mathrm{H}_{2} \mathrm{DCN}$ と反応し, $\mathrm{HgBr}^{+}+\mathrm{H}_{2} \mathrm{DCN} \rightleftarrows(\mathrm{HgBr})$ $\mathrm{HDCN}+\mathrm{H}^{+}$によって赤紫色の錯体 $(\lambda=562 \mathrm{~nm})$ を形 成するとしている.

水銀試薬 $\left(\mathrm{Hg}^{2+}+\mathrm{Br}^{-}\right)$中には $\mathrm{Hg}^{2+}, \mathrm{HgBr}^{+}, \mathrm{HgBr}_{2}$, $\mathrm{HgBr}_{3}-, \mathrm{HgBr}_{4}{ }^{2-}$ のすべてが存在している $\left.{ }^{12}\right)$ が実験濃度 範囲では $\mathrm{HgBr}_{3}{ }^{-}, \mathrm{HgBr}_{4}{ }^{2-}$ は無視できる推算 : $f_{\mathrm{HgBr}^{+}}$ $\left.\cong 0.6, f_{\mathrm{Hg}^{2+}} \cong f_{\mathrm{HgBr}_{2}} \cong 0.2\right\}$. 奥谷 ${ }^{13)}$ によれば $\mathrm{Hg}^{2+}+$ $\mathrm{Br}$ 一を用いる改良法に怙ける主反応は上記, 試薬反応 のほか, 定量反応 $\left(\mathrm{Cl}^{-}\right.$-が存在するとき) として, $(\mathrm{Hg}$ $\mathrm{Br}) \mathrm{HDCN}+2 \mathrm{Cl}-\rightleftarrows \mathrm{HgCl}_{2}+\mathrm{Br}^{-}+\mathrm{HDCN}$-を考光て いる. この場合, DC 試薬添加前の水相中には $\mathrm{Hg}^{2+}$, $\mathrm{HgCl}^{+}, \mathrm{HgCl}_{2}, \mathrm{HgBr}^{+}, \mathrm{HgBr}_{2}$ などのイオン種あるい は分子種が存在しているが, 濃度及び安定度定数の大き さから，塩化物としては $\mathrm{HgCl}_{2}$ が，臭化物としては $\mathrm{HgBr}^{+}{ }^{-}$が相対的に多く存在していると考兄られるので 不自然なものではない，ただ，水銀試薬として $\mathrm{Hg}^{2+}+$ $\mathrm{HgBr}_{2}$ を用いた場合の分析反応は，現在のところ明らか ではない. $\mathrm{HgBr}_{2}$ は Fig. 2 でも示したよらに難解離性 であり，一部は $\mathrm{HgBr}_{2} \rightleftarrows \mathrm{HgBr}^{+}+\mathrm{Br}^{-}$, 及び $\mathrm{HgBr}_{2}+$ $\mathrm{Hg}^{2+} \rightleftarrows 2 \mathrm{HgBr}^{+}$などの反応が生じるとしても，特に $\left[\mathrm{Hg}^{2+}\right]_{0}=2\left[\mathrm{HgBr}_{2}\right]_{0}$ のとき,なぜ検量線の直線性が最 も良好となるかは説明できない。

$$
\text { ところで, 著者らは } \mathrm{H}_{2} \mathrm{DCN}(\phi-\mathrm{NH}-\mathrm{NH}-\mathrm{O}-\mathrm{C}-\mathrm{N}=\mathrm{N}-\phi)
$$
は $\mathrm{Hg}^{2+}$ と錯形成して $\mathrm{H}^{+}$を放出する $\left(\mathrm{Hg}^{2+}+\mathrm{H}_{2} \mathrm{DCN}\right.$ $\left.\rightleftarrows \mathrm{HgDCN}+2 \mathrm{H}^{+}\right) \quad$ が, $\mathrm{H}_{4} \mathrm{DCN}(\phi-\mathrm{NH}-\mathrm{NH}-\mathrm{C}-\mathrm{O}-\mathrm{NH}-$ $\mathrm{NH}-\phi)$ は $\mathrm{Hg}^{2+}$ とは反応しないといら説明11) とやや疑 問をいだいた，そこで，水銀試薬 $\left\{1.0 \times 10^{-4} \mathrm{M}\right.$ 及び
$1.0 \times 10^{-2} \mathrm{M}$ 硝酸水銀(II) $\} 10 \mathrm{ml}$ を採取し，水で希釈 し全量を $100 \mathrm{ml}$ とし, 初期 $\mathrm{pH}$ を酸性, 中性, 塩基性 として DG 試薬を徐々に添加していったところ，水銀 と等モル以上の添加によっても $\mathrm{pH}$ 变化はほとんどな く,むしろ, わずかながら $\mathrm{pH}$ 上昇が認められた。こ の結果から, $\mathrm{Hg}^{2+}$ と $\mathrm{H}_{2} \mathrm{DCN}$ の錯形成反応はプロト ンの放出を伴わないものと推定される.

なお，上では述べなかったが，ベンゼンの代わりにク ロロホルムも使用できる. 更に特に指摘して执きたいの は DC 試薬である. 近年, 各試楽製造会社の製品の品 質は向上しているが，DC 試薬に関しては製造会社間の 差が大きい(9)10). 本研究では原則として一社のものを使 用したが， $\mathrm{H}_{2} \mathrm{DCN}-\mathrm{H}_{4} \mathrm{DCN}$ のモル比が $1: 1$ 亿近い他 社製品を使用したところ, 極めて安定であり, 又低濃度 $(0.01 \mathrm{~g} / 100 \mathrm{ml}$ エタノール) でも高い吸光度が 得られ た。

終わりに，本研究の実験の一部を協力していただいた 九州工業大学浜地洋己氏に感謝いたします. 又, 種々の 観点から議論並びに御教示いただいた日本大学理工学部 奥谷忠雄教授に，更に錯体について御教示いただいた九 州工業大学工学部坂田一矩助教授に感謝いたします。

$(1987$ 年 4 月, 日本化学会第 (54 春季年会において一部発表)

\section{交献}

1) 内海 喻: 日化, 73, 835 (1952).

2）友成明久:日化, 83，693，696 (1962).

3）友成明久：日化，82，864(1961).

4) 内海 喻, 奥谷忠雄: 日化, 85, 543 (1964).

5) R. J. Bertolacini, J. E. Barney : Anal. Chem., 30, 202, 498 (1958). D. F. Boltz, J. A. Howell, ed. : "Colorimetric Determination of Nonmetals", 2nd ed., p. 94 (1978), (John Wiley, New York).

6) Y. Yamamoto, K. Kotsuji : Bull. Chem. Soc. Jpn., 37, 594 (1964).

7）日本分析化学会編：“分析化学便覧（改訂三版）”, p. 191 (1981), (丸善).

8）辻 啓一訳：“緩衝液の選択と応用”， p. 132 (1981), (講談社); \{D. D. Perrin, B. Dempsey: "Buffers for $p H$ and Metal Ion Control", (1974), (Chapman and Hall, London)\}.

9) 長島 潜, 町田 霜, 内海 喻: 分析化学, 33, 265 (1984).

10) 長島 潜, 町田 霜, 中山憲子, 内海 睮: 分析 化学, 33, 533 (1984).

11) T. Okutani : Bull. Chem. Soc. Jpn., 41, 1728 (1968).

12）藤原鎮男監訳：“コルトフ分析化学”，IV，p. 980 (1975), (廣川書店); \{I. M. Kolthoff, E. B. Sandell, E. J. Meehan, S. Bruckenstein: "Quantitative Chemical Analysis" 4th ed., (1969), ( Macmillan Company, New York)\}. 
13）奥谷忠雄：私信 (1987).

\section{ș}

Improvement of diphenylcarbazone method for determination of small amounts of chloride ion. Tetsutaro Yoshinaga, Toshimi Iura and Kentaro Kawano (Department of Environmental Chemistry, Faculty of Engineering, Kyushu Institute of Technology, 1-1, Sensuicho, Tobata-ku, Kitakyushu-shi, Fukuoka 804)

The diphenylcarbazone method proposed by Tomonari, and Utumi et al. is very useful for the determination of low concentrations of chloride ion $(0 \sim 1.0 \mathrm{mg} / \mathrm{l})$. However, the reproducibility of the method is not satisfactory. We studied about the factors affecting the absorbance of $\mathbf{H g}(\mathrm{II})$-diphenylcarbazone complex. The process were as follows: under constant temperature (preferably less than $20^{\circ} \mathrm{C}$ ) and sufficient shielding from light, $2 \mathrm{ml}$ of the $\mathrm{Hg}(\mathrm{II})$ reagent $\left\{1.0 \times 10^{-4} \mathrm{M} \mathrm{Hg}\left(\mathrm{NO}_{3}\right)_{2}\right.$ $\left.+0.5 \times 10^{-4} \mathrm{M} \mathrm{HgBr}_{2}\right\}$ in $1 \times 10^{-2} \mathrm{M} \mathrm{HNO}_{3}$ solution was added to $10 \mathrm{ml}$ of the sample solution with $0 \sim 1.0$ $\mathrm{mg} / \mathrm{l} \mathrm{Cl}^{-}$. Ten $\mathrm{ml}$ of benzene was added followed by the addition of $2 \mathrm{ml}$ of diphenylcarbazone reagent ( $0.05 \mathrm{~g}$ diphenylcarbazone-diphenylcarbazide equimolar mixture/100 ml EtOH). The mixture was allowed to stand for more than $15 \mathrm{~min}$ before shaking at constant rate (e.g. 180 times $/ \mathrm{min}$ ) for $30 \mathrm{~s}$. After shaking, the mixture was again made to stand for $5 \mathrm{~min}$ and the organic phase was separated and the absorbance of the extracted complex $\{\mathrm{Hg}(\mathrm{II})$-diphenylcarbazone complex $\}$ was finally measured at $560 \mathrm{~nm}$. By the above procedure, good reproducibility for making a calibration curve was obtained with better linearity. The relative standard deviation was $1.6 \%$ at $\left[\mathrm{Cl}^{-}\right]=1.0 \mathrm{mg} / \mathrm{l}(n=6)$. The analytical reactions involved were also discussed.

(Received September 9, 1987)

\section{Keyword phrases}

basic study of diphenylcarbazone method; determination of chloride in solution; visible ray; investigations of factors for reproducibility; improvement in $\mathrm{Hg}$ (II) reagent. 